\title{
Fractionation of Manganese in Soil Samples Collected From the Lakhra Coal Field in Pakistan Using Two Modes of Atomic Absorption Spectrometry
}

\author{
Mustaqeem ur Rahman, Tasneem G. Kazi*, Huma Shaikh, and Jamshed Ali \\ National Centre of Excellence in Analytical Chemistry, University of Sindh, \\ Jamshoro 76080, Pakistan
}

\section{INTRODUCTION}

Coal mining and coal processing are of profound environmental concern due to the generation of large quantities of dust particles and mine spoil containing toxic elements dispersed in the dust and soils with potentially adverse health impact on nearby inhabitants of the mines. Open-throw coal mining results in huge quantities of dust and gas emissions containing metals and metalloids in very low quantities. When coal is combusted for energy production, as for the thermal power plants, the metal concentrations increase considerably (1). The waste from coal (ash) near power plants contains elevated levels of elements (As, Cr, Mn, V, Pb, and $\mathrm{Zn}$ ) which can adversely influence the soil quality and flora and fauna of the area (2).

In this study, manganese (Mn) is selected because of its high exposure especially to miners and causes neurological disorders such as Parkinson's disease. Manganese is an essential trace element (at normal levels (2.0 to $5.0 \mathrm{mg} / \mathrm{minimum}$ daily allowance) and is required for normal physiological functions, especially related to the reproductive functions. A deficiency of Mn can cause skeletal abnormalities and irregular metabolism of carbohydrates and lipids.

Establishing the trace toxic elements found around thermal power plants due to coal burning for energy production can provide valuable information about possible

Corresponding autbor.

E-mail: tgkazi@yaboo.com

Tel: +92 22-2772065, 9213429

Fax: + 92 22-9213431

\section{ABSTRACT}

The fractionation of manganese (Mn) in soil samples of three coal mining areas was carried out using Community Bureau of References sequential extraction (BCR-SE) method. The BCR-SE provides information about extractable $\mathrm{Mn}$, bound in different chemical forms such as the acid-soluble $0.11 \mathrm{~mol} \mathrm{~L}^{-1}$ acetic acid, the reducible fraction requires $0.1 \mathrm{~mol} \mathrm{~L}^{-1}$ hydroxylammonium chloride, and $\mathrm{Mn}$ bound with the oxidizable fraction of $8.8 \mathrm{~mol} \mathrm{~L}^{-1}$ requires hydrogen peroxide plus ammonium acetate $\left(1.0 \mathrm{~mol} \mathrm{~L}^{-1}\right)$, respectively. The Lixiviation test (DIN 38414-S4) was also carried out to evaluate the leachable Mn content in all three soil samples. The total Mn in the soil samples (pseudo-total content) was determined by the digestion of the soil samples with aqua regia. The total concentration of Mn obtained from all four chemical fractions of the BCR-SE method was evaluated.

The Mn bound to the different chemical fractions was determined by flame and electrothermal atomic absorption spectrometry. The $\mathrm{pH}$ of the soil of the three mining areas was in the range of 6.2-6.8. The major fraction of Mn was found in the reducible fractions, whereas the organically bound form was lower for the three soil samples. The sequence of the chemical forms was in decreasing order: $\mathrm{Mn}_{\text {reducible }}<\mathrm{Mn}_{\text {residual }}<\mathrm{Mn}_{\text {oxidizable }}$ $<\mathrm{Mn}_{\text {acid-soluble }}$ which indicates that the major form of Mn was in poorly available form. contamination in the air and soil, as well as the surface and groundwater systems $(3,4)$. Availability of toxic elements depends on the surface characteristics of the coal particles, the chemical bonding forms, as well as the type and concentration of the solution used for extraction (5). Soil and water reservoirs are frequently contaminated with inorganic and organic pollutants causing adverse effects on food crops and plants (6).

Manganese is not found in free form, but in different chemical compounds together with carbonates, sulfides, phosphates, oxides, borates, and silicates (7). The metal accumulation in coal is due to degraded plant material and the soil. It has been reported (8) that burning of coal converts the metals and metalloids to less volatile or stable forms. On cooling, the volatilized metal and metalloid vapors settle onto the surface of the soil. Thus, these elements might be more mobile than in their original form in the coal samples.

The elements generally found in environmental samples are due to natural and anthropogenic sources and are in different chemical forms. For the chemical fractionation of Mn and other metals in soil, residual and fly ash, the BCR sequential extraction scheme is generally used and consists of four steps: acid-soluble, reducible, oxidizable, and residual. Manganese is found in three potential oxidation states in soil and fly ash: Mn(II), Mn(III), and Mn(IV). The most stable form is the divalent ion of Mn(II), whereas Mn(III) and Mn(IV) are stable only in solid form. (9-11). 
The extraction of the easily available/bioavailable fraction of metals in environmental solid samples requires mild neutral salt solutions of $\mathrm{NaNO}_{3}, \mathrm{KNO}_{3}, \mathrm{CaCl}_{2}, \mathrm{CH}_{3} \mathrm{COONH}_{4}$ and EDTA, whereas water-soluble metals are in an immediately available form for plants. Thus, to obtain information about metals in their different chemical forms, the binding characteristics of the ingredients, and their possibility of transport, requires a multistage extraction method (12).

The availability of $\mathrm{Mn}$ in soil is controlled by its redox potential and the soil $\mathrm{pH}$, where the lower $\mathrm{pH} /$ redox potential reduces its insoluble form and enhances its mobility. When the soil $\mathrm{pH}$ is $>6$, $\mathrm{Mn}$ is most probably bound with organic matter, oxides, and silicates which reduces its solubility. The solubility and availability of $\mathrm{Mn}$ is, therefore, normally low at a high $\mathrm{pH}$ and with high organic matter content, whereas at low pH (acid soils) and a low quantity of organic matter the availability of $\mathrm{Mn}$ is high. At anaerobic and aerobic conditions at $\mathrm{pH}>6$ and below 5.5, the solubility of Mn is high (13).

This study was carried out at the coal mining area within the district of Jamshoro, Sindh, Pakistan, to assess the potential human exposure risks due to $\mathrm{Mn}$ in the surrounding soil. The soil samples were collected from three mining zones of the Lakhra power plant. The three-stage sequential extraction scheme was used. In addition, the determination of the water-soluble elements in these soil samples was carried out using the German Standard Method (DIN 38414-S4) (14).

\section{EXPERIMENTAL}

\section{Instrumentation}

The total concentration and fractionation of Mn with digests and using the BCR-SES method was performed using the AAnalyst ${ }^{\mathrm{TM}} 700$ double beam flame atomic absorption spectrometer (FAAS) (PerkinElmer, Inc., Shelton, CT, USA), equipped with a pyrocoated graphite tube and integrated platform, and an AS-800 autosampler. Centrifugation was carried out using a Model 1465 centrifuge (speed range 0-6,000 rpm, timer 0-60 minutes, 220/50 HZ, Histam$\mathrm{R}$, Spain). Also used for the experimental work were an electric shaker (Gallenkamp, Germany), digital pH-meter (WTW Inolab pH 740 meter, Germany), digital conductivity meter (WTW Inolab EC 720 meter, Germany), and a muffle furnace. The instrumental operating parameters are listed in Table I.

\section{Sampling}

The samples were taken from the surface soil layer $(0-25.0 \mathrm{~cm})$,

TABLE I

Instrumental Parameters for Flame and Electrothermal Atomic Absorption Spectrometer for the Determination of Mn

\begin{tabular}{ccccc}
\hline Metal & $\begin{array}{c}\text { Wavelength } \\
(\mathrm{nm})\end{array}$ & $\begin{array}{c}\text { Aanalyst 800 Flame AAS Program Used } \\
(\mathrm{mA})\end{array}$ & $\begin{array}{c}\text { Bandpass } \\
(\mathrm{nm})\end{array}$ & $\begin{array}{c}\text { Air Acetylene } \\
\text { Flow Rate } \\
\left(\text { min }^{-1}\right)\end{array}$ \\
\hline Mn & 279.5 & 15 & 0.2 & $11: 1$ \\
\hline Metal & $\begin{array}{c}\text { Wavelength } \\
(\mathrm{nm})\end{array}$ & $\begin{array}{c}\text { SAnalyst 800 Furnace AAS Program Used } \\
\text { Spectral Bandwidth } \\
(\mathrm{nm})\end{array}$ & $\begin{array}{c}\text { Lamp Current } \\
(\mathrm{mA})\end{array}$ & $\begin{array}{c}\text { Background } \\
\text { Corrector }\end{array}$ \\
\hline Mn & 279.5 & 0.2 & 7 & On \\
\hline
\end{tabular}

collected during 2017 from the three coal mining areas $(n=20$ each), air-dried at room temperature for about 8 days. Then they were screened through a Nylon 2 $\mathrm{mm}$ sieve (purchased at a local market), made into 10 composite samples from each site, and stored in polypropylene containers at ambient temperature until analysis.

\section{BCR Sequential Extraction Method}

For the modified BCR four-stage sequential extraction, different extracts and extraction settings were used (Table II). For the modified BCR-SE scheme, a higher concentration of reagent $(20 \mathrm{~mL}$ of hydroxyl amine hydrochloride) was used for the reducible fraction of Mn.

For replicate analysis, three samples of the air-dried composite soil samples (collected from the Lakhra coal mining area) were used. For all extraction steps, blank experiments (without standards/samples) were carried out.

The samples in the flasks were shaken at $30 \mathrm{rpm}$ with a mechanical shaker at $25-30^{\circ} \mathrm{C}$ (room temperature) which is higher than the temperature $\left(20^{\circ} \mathrm{C}\right)$ generally used and reported in the literature (15). Owing to the temperature and climate of the study area, the weight of the soil samples and the quantity of the extracting solutions were reduced. However, the proportion of solid solution used was similar to what was reported in the literature (11). Information about the experimental procedure is accessible elsewhere (16).

The experimental and extraction steps used in this study are listed in Table II. For calculation of the Mn levels in the soil samples, duplicate soil samples from each site were heated in an oven at $100 \pm 5^{\circ} \mathrm{C}$ until a stable weight was obtained. Thus, the obtained analytical value at each step was based on dry basis 
(mg kg-1 of the metals according to dry weight of soil).

The extraction of Mn was carried out in all four steps/chemical fractions using different reagents. It was, therefore, not possible to provide a calibration graph with a simple standard of Mn salt. For this purpose, the extractant after each step was evaporated at $80{ }^{\circ} \mathrm{C}$ on an electric hot plate until a semi-residual mass was obtained. The residual mass was diluted with $0.2 \mathrm{~N} \mathrm{HNO}_{3}$ and filtered through a \#42 Whatman filter to obtain the same matrixes for both the standards and the samples.

\section{Leaching Test (DIN 38414-S4)}

The water-soluble fraction of the metals in the environmental solid samples was determined using the German Standard Method DIN 38414-S4. Leaching of Mn was performed by adding ultrapure water to duplicates of each composite soil sample at a ratio of $(1: 10)$, and were left standing for 16 hours at room temperature. Then, the samples were filtered to separate the residual soil from the extractant, then filtered through a prewashed membrane filter of pore size 0.45 $\mu \mathrm{m}$. The $\mathrm{pH}$ values, electrical conductivities, and concentrations of the extracted Mn were measured by electrothermal atomic absorption spectrometry (ETAAS).

\section{Quality Parameters}

Due to the unavailability of a certified reference material for $\mathrm{Mn}$ in soil, the validity of the BCR sequential extraction method was assessed using three replicate subsamples of soil collected from the three mining areas, spiked with known standards at two concentration levels. The accuracy was further confirmed by analyzing triplicates of each composite soil sample. The recoveries

\section{TABLE II}

Chemical Reagents and Extraction Conditions for Optimized BCR-SES and Aqua Regia Digestion of Soil Samples

Steps

1. Acid-soluble $20 \mathrm{~mL}$ of $0.11 \mathrm{M}$ acetic acid was added to $0.5 \mathrm{~g}$ of air-dried IWS and CRM samples, shaken for 12-24 hours. The mixture was centrifuged to separate the extract from the residue.

2. Reducible $20 \mathrm{~mL}$ of freshly prepared hydroxyl ammonium chloride, adjusted with nitric acid to $\mathrm{pH} 1.5$, was added to the residue from Step 1, and the extraction performed as above.

3. Oxidizable The residue from step 2 was treated twice with $5 \mathrm{~mL} \mathrm{30 \%} \mathrm{hydrogen} \mathrm{peroxide,}$ evaporated to near dryness, and then $25 \mathrm{~mL}$ of ammonium acetate (adjusted to $\mathrm{pH} 2$ with nitric acid) was added and the extraction performed as above.

4. Residual $8 \mathrm{~mL}$ of aqua regia $\left(\mathrm{HCl} / \mathrm{HNO}_{3}, 3: 1\right)$ was added to residue obtained after the third step, and digested on a hot plate at $100{ }^{\circ} \mathrm{C}$ as described below.
Exchangeable, water and acid,and acid soluble, (e.g., carbonates)

Reducible (e.g., organic substance and sulfides)

Oxidizable (e.g., organic substance and sulfides)

Remaining nonsilicate-bound metals for the spiked Mn were usually quantitative, whereas the extraction recoveries of $\mathrm{Mn}$ were found to be lower for the oxidizable fraction where somewhat low recoveries were obtained, but the difference was not significant $(p<0.05)$. The percentage recovery of the spiked Mn in each fraction of BCR was in the range of $97.1-98.4 \%$, indicating a non-significant difference $(\mathrm{p}>0.05)$ (see Table III). Furthermore, the accuracy of the sequential extraction of Mn obtained by the sum of its concentrations was found good and compared well with the total concentrations directly determined from the corresponding soil samples, also termed pseudo-total. The recovery(\%) of $\mathrm{Mn}$ was calculated as:

$$
\text { Recovery (\%) }=\frac{\sum \text { of four fractions }}{\text { Pseudo-total contents }} \times 100
$$

\section{RESULTS AND DISCUSSION}

\section{Mn Fractionation in the Soil Samples}

The four-step BCR sequential extraction scheme provides the chemical forms of the metals, informs of their availability, mobilization, and transportation of $\mathrm{Mn}$ from different soil samples to the environment, especially into groundwater. For the present sequential extraction steps corresponding to soluble Mn in weak acid (acid-soluble) form, hydroxyl ammonium chloride was used as the extractant and termed as the reducible fraction, whereas the third chemical fraction was the oxidizable form.

Sequential extraction procedures provide useful information for risk assessment of the metals and to estimate the amount of metals mobilized under different environmental conditions (weakly acidic conditions: Step 1, reducing conditions: Step 2, and oxidizing conditions: Step 3). The different chemically bound forms or distribution 
patterns of Mn are listed in Table IVa. It was observed that the major amount of Mn is stable and not extracted by water. However, a very small percentage $(0.337$ $0.507 \%)$ of the total concentration of Mn was soluble in water (Table IVa).

The first fraction of BCR-SES (acid-soluble metals) in general has comparatively little concentration of metals and is determined by electrothermal atomic absorption spectrometry (ETAAS). For the acidsoluble fraction of $\mathrm{Mn}$, a $0.11 \mathrm{M}$ of $\mathrm{CH}_{3} \mathrm{COOH}$ was used. The mild concentration of acid can dissolve the Mn bound with the carbonate com- pounds, which does not react or dissolve the Mn bound with alumino silicates, organic matter, Fe and Mn oxides (17).

The concentration of $\mathrm{Mn}$ in the acid soluble/carbonate fraction was in the range of 5.2 to $5.74 \%$ of total content in the different soil samples, which might be considered as the more mobile and bio-available form for plant uptake. The chemical fraction of the metals, which precipitate or co-precipitate with carbonate compounds, are easily extracted out with a mild concentration of acid. It was reported that metals found in this fraction bind loosely with the carbonate form

TABLE III

Standard Addition/Recovery for Mn Fractions in Real Soil Samples From PMDC Mining Areas of Lakhra Coal Field

\begin{tabular}{|c|c|c|c|c|c|c|c|c|}
\hline $\begin{array}{c}\text { Added } \\
\text { Mn } \\
(\mathrm{mg} / \mathrm{L}) \\
\end{array}$ & $\begin{array}{l}\text { Acid- } \\
\text { soluble }\end{array}$ & $(\%) R^{b}$ & Reducible & $(\%) \mathrm{R}$ & Oxidizable & $(\%) \mathrm{R}$ & Residual & $(\%) \mathrm{R}$ \\
\hline 0.0 & $8.4 \pm 0.71^{\mathrm{a}}$ & & $110 \pm 6.53$ & & $16.0 \pm 1.02$ & & $84.0 \pm 4.4$ & \\
\hline 5.0 & $13.1 \pm 1.2$ & 97.6 & $112.7 \pm 8.2$ & 98.0 & $20.4 \pm 1.23$ & 97.1 & $87.0 \pm 2.7$ & 98.2 \\
\hline 10.0 & $18.1 \pm 1.71$ & 98.4 & $117.6 \pm 7.47$ & 97.8 & $25.5 \pm 1.65$ & 98.1 & $92.0 \pm 5.2$ & 97.9 \\
\hline
\end{tabular}

${ }^{a}$ Means of six replicates with standard deviations.

b (\%)Recovery.

TABLE IVa

Fractionation of Mn in Soil Samples of Different Coal Mining Areas

\begin{tabular}{llllll}
\hline $\begin{array}{l}\text { Soil Sample/ } \\
\text { Fractions }\end{array}$ & $\begin{array}{c}\text { Water- } \\
\text { soluble }\end{array}$ & $\begin{array}{c}\text { Acid- } \\
\text { soluble }\end{array}$ & Reducible & Oxidizable & Residual \\
\hline S1 (mg/kg) & $1.12 \pm 0.15$ & $8.42 \pm 0.451$ & $106 \pm 7.65$ & $16.0 \pm 1.12$ & $82.4 \pm 6.74$ \\
\% of Total & 0.507 & 5.74 & 49.2 & 7.407 & 37.1 \\
S2 & $2.2 \pm 0.12$ & $27.6 \pm 1.76$ & $240 \pm 14.4$ & $42.5 \pm 1.21$ & $191 \pm 16.8$ \\
\% of Total & 0.439 & 5.24 & 48.1 & 8.383 & 38.12 \\
S3 & $0.98 \pm 0.028$ & $16.1 \pm 1.12$ & $140 \pm 11.8$ & $21.1 \pm 1.81$ & $113 \pm 7.34$ \\
\% of Total & 0.337 & 5.5 & 48.2 & 7.26 & 38.9 \\
\hline \multicolumn{7}{c}{ TABLE IVb } \\
Sample & $\sum$ of Four Fractions & Pseudo-total & (\%) Relative Errors \\
\hline S1 & 217 & 221 & & 1.81 \\
S2 & 501 & 502 & & 0.063 \\
S3 & 290 & 291 & & 0.371 \\
\hline
\end{tabular}

S1= Pakistan Mineral Development Corporation.

S2= Irfan Coal Mine.

S3= Indus Coal Mine.

\section{Atomic Apectroscopy \\ 1 Vol. 39(6), Nov./Dec. 2018}

and are easily available when environmental conditions (such as $\mathrm{pH}$ ) change $(18,19)$.

The highest amount of Mn (45.6 to $48.2 \%$ of total $\mathrm{Mn}$ ) was observed for the reducible fraction. Thus, the Mn bound with the iron-Mn oxide lattice is liberated when the matrices of the environmental samples are treated at reducing environment by means of reducing agent hydroxyl ammonium chloride (20). It was reported that the amount of iron-Mn oxides is higher in sediment and soil samples, but less in solid samples enriched with organic matter (21).

The oxidizable fraction was found to be lower than the Mn bound with iron-manganese oxide in the soil samples collected from the coal mining areas. The $\%$ of $\mathrm{Mn}$ bound with organic matter of the oxidizable Mn corresponds to 7.26 to $8.38 \%$ of its total concentration in all three soil samples. The metals bound with the organic portion of the solid samples become available when treated with the oxidizing reagents. It can be stated that the metals are not easily available because they are bound with the humic substances and have, therefore, high molecular weight, and to liberate small amounts of metals requires a long time period (22). It was reported that the deprivation of metals in an oxidizing environment can be due to their decomposition in organic matter and releases them into the environment (23). It was also noted that the divalent metal ions, in comparison to monovalent ions, have elevated selectivity for compounds that are organic in nature.

The hydrogen peroxide in acid medium is mostly used for the third fraction (oxidizable) of the BCR-SES method. The residual fraction of $\mathrm{Mn}$ in the three composite soil samples is partitioned in the residual phase corresponding to 37.1 to $39 \%$ of total concentration. The 
residual fraction is bound to a stable lattice structure in the environmental solid samples. The concentrations of the chemical fractions of $\mathrm{Mn}$ in the soil samples were found in decreasing order: Acid-soluble Mn > Oxidizable Mn > Residual Mn $>$ Reducible Mn. The leachable fraction of Mn collectively with the other two fractions, acid-soluble and oxidizable fraction, was usually not found to be very elevated in the sediment and soil samples. The comparison of the sum of concentrations of $\mathrm{Mn}$ in all four fractions of the BCR procedure to the total concentrations obtained after digestion with the acid mixture is shown in Table IVb.

Another significant feature of the fractionation data is the ability to obtain the percentage of the labile concentration of the metals in the environmental solid samples (soil and sediment). It is equivalent to the sum from fractions $1-3$, the total concentrations obtained from all fractions of BCR-SES (including the residual concentration). The resulting data indicated that the labile fraction of $\mathrm{Mn}$ in the soil samples was $>60 \%$. It was reported that in general if the percent values obtained from the sum of the first three fractions are higher than the residual concentrations, larger adverse effects occur that contaminate the water bodies and bio-accumulate in plants (24).

Elevated levels of metals available/mobile as extracted in mild extractants might easily enter into the soil to contaminate agricultural systems. The mobile/bio-available contents of Mn in the soil samples are particularly susceptible to conditions such as wetness, content of organic material, biological activity, $\mathrm{pH} /$ acidity, etc. The soluble fraction of $\mathrm{Mn}$ in soil might be restricted by its $\mathrm{pH}$ and redox potential, whereas at lower values of both factors $(\mathrm{pH}$ and redox potential) it helps to enhance the mobility of Mn.
When at higher $\mathrm{pH}(\mathrm{pH}>6.0)$, the Mn solubility/bio-availability is decreased, which might be due to the association of Mn bound with oxides, silicates, and organic matter. At lower levels of organic matter and higher $\mathrm{pH}$ of the environmental solid samples, the availability/solubility of $\mathrm{Mn}$ is lowered.

However, at lower $\mathrm{pH}$ (acidic soil), the solubility of $\mathrm{Mn}$ in an aqueous medium is higher. This study found that at anaerobic conditions of soil/sediment samples at $\mathrm{pH}>6$ (while aerobic conditions at $\mathrm{pH}$ $<5.5)$, the availability/solubility of Mn becomes enhanced at the $\mathrm{pH}$ above 6 as well as in aerobic conditions at the $\mathrm{pH}$ below 5.5 (25).

To evaluate the available/bioavailable concentration of metals in different environmental solid samples, mild extractants are used such as $\mathrm{H}_{2} \mathrm{O}, \mathrm{CaCl}_{2}, \mathrm{NH}_{4} \mathrm{NO}_{3}, \mathrm{NaNO}_{3}$, and EDTA as single extractant. Whereas for metals and metalloids bound to different chemical lattices of environmental samples, different sequential extraction schemes are selected. Although Mn is an essential trace element and necessary for different physiological systems in trace quantities, high intake/exposure becomes a negative and can occur through the contamination of drinking water, food crops, as well as due to burning fossil fuels.

\section{CONCLUSION}

The data obtained in this study indicates that the Mn concentration in all soil samples from the three different locations of the coal mining areas of the Lakhra coal fields were found in stable form and only $<1 \%$ of the total concentration was immediately available to plants and the neighboring inhabitants of the area. The highest concentration of Mn was found in the reducible fraction and showed an association with soil $\mathrm{pH}$. The metal can become bio-available to plants with a change in the redox or $\mathrm{pH}$ condi- tions of the soil. In coal mining areas, the Mn levels must be monitored to protect man and the environment.

Received April 2, 2018.

\section{REFERENCES}

1. R.E. Masto, L.C. Ram, J. George, V.A. Selvi, A.K. Sinha, S. K Verma, T.K. Rout, and Priya Darshini, Toxicol. Environ. Chem. 93, 223 (2010).

2. L. Bityukova, A. Shogenova, and $M$. Birke, Environm. Geochem.and Health 22, 2 (2000).

3. R.B. Finkelman, W. Orem, V. Castranova, C.A. Tatu, H.E. Belkin, B.Zheng, and A.L.Bates, Internatl. J. Coal Geology 50(1-4), 425 (2002).

4. Y. Tang, C. Chang, Y. Zhang, and W. Li, Energy Exploration \& Exploitation 27(2), 143 (2009).

5. Kalembkiewicz, J., Sitarz-Palczak, E., and Zapała, L. Microchem. J. 90(1), 37 (2008).

6. George, Joshy, Reginald E. Masto, Lal C. Ram, Tarit B. Das, Tofan K. Rout, and Mahesh Mohan. Archives of Environmental Contamination and Toxicology, 68(3), 451 (2015).

7. Gerber, G. B., Leonard, A., and Hantson, P. Critical Reviews in Oncology/Hematology 42(1), 25 (2002).

8. Kalembkiewicz, J., Sitarz-Palczak, E., and Zapała, L., Microchem. J. 90(1), 37 (2008).

9. Gerber, G.B., Leonard, and A. Hantson, P., Critical Reviews in Oncology/Hematology 42, 25 (2002).

10. Howe, P., Malcolm, H. and Dobson, Environmental Aspects, World Health Organization, Geneva, Switzerland, pp. 63 (2004).

11. Grygo-Szymanko, Emilia, Anna Tobiasz, and Stanislaw Walas, "Speciation analysis and fractionation of manganese: A review", TrAC Trends in Analytical Chemistry (2016). 


\section{Atomic \\ $\bigcirc$ Vol. 39(6), Nov./Dec. 2018}

12. Howe, P., Malcolm, H., and Dobson, S. environmental aspects (No. 63). World Health Organization (2004).

13. Kabata-Pendias, A., Trace elements in soils and plants, CRC Press (2010).

14. DIN 38414-S4. German standard methods for the examination of water, wastewater and sludge. Group S (sludge and sediments). Determination of leachability by water (S4). Deutsches Institut für Normung, Berlin, Germany (1984).

15. Pueyo, M., Rauret, G., Lück, D., Yli-Halla, M., Muntau, H., Quevauviller, P., and López Sánchez, J. F., Journal of Environmental Monitoring 3(2), 243 (2001).

16. Kazi, T. G., Jamali, M. K., Kazi, G. H., Arain, M. B., Afridi, H. I., and Siddiqui, Anal. and Bio-anal. Chem. 383(2), 297 (2005).

17. Rauret, G., López-Sánchez, J. F., Sahuquillo, A., Barahona, E., Lachica, M., Ure, A. M., and YliHalla, M., J. of Environm. Monitoring 2(3), 228 (2000).
18. Ali, J., Kazi, T. G., Baig, J. A., Afridi, H. I., Arain, M. S., Brahman, K. D., and Panhwar, A. H., Environmental Science and Pollution Research 22(11), 8559 (2015)

19. Emmerson, R. H. C., Birkett, J. W., Scrimshaw, M., and Lester, J. N., Science of the Total Environment 254(1), 75 (2000).

20. García-Miragaya, J., and Sosa, A. M., Water, Air, and Soil Pollution, 77(12), 141 (1994).

21. Davidson, C. M., Wilson, L. E., and Ure, A. M., J. of Anal. Chem. 363(1), 134 (1999).

22. Sutherland, R. A., and Tack, F. M., Anal. Chim. Acta 454(2), 249 (2002).

23. Michalke, K. and Fernsebner, J., Trace Elem. Med. Biol. 28, 106 (2014).

24. P. Anschutz, K. Dedieu, F. Desmazes, and G. Chaillou, Chem. Geol. 218, 265 (2005).

25. Sutcu, E.C., Karayigit, A. I., Internatl. J. of Coal Geol. 144-145, 111 (2015).

\section{*RC Press/Taylor \& Francis announces the availability of}

\section{Measuring Elemental Impurities in Pharmaceuticals: A Practical Guide}

Robert J. Thomas, CSci, CChem, FRSC Principal Consultant Scientific Solutions Gaithersburg, MD

\footnotetext{
- The complete guide to measuring elemental impurities in pharmaceutical and nutraceutical materials.

- Covers heavy metals testing in the pharmaceutical industry from an historical perspective.

- Gives an overview of current USP Chapters <232><233> and <2232> and ICH Q3D Step 4 Guidelines.

- Explains the purpose of validation protocols used in Chapter <233>, including how J-values are calculated

- Describes fundamental principles and practical capabilities of ICP-MS and ICP-OES.

- Offers guidelines about the optimum strategy for risk assessment.

- Provides tips on how best to prepare and present your data for regulatory inspection.
}

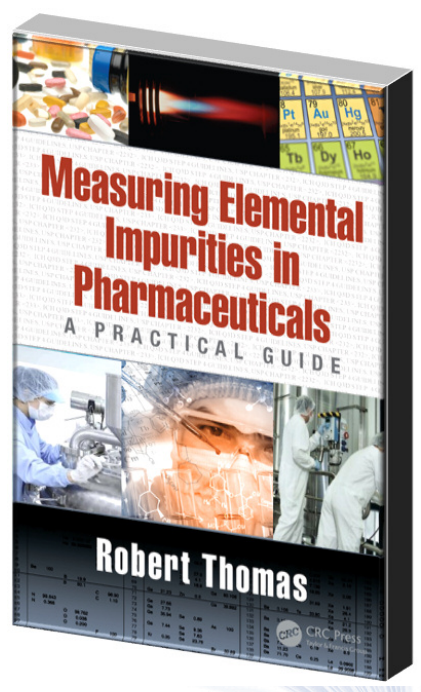

\section{Online www.crcpress.com}

